\title{
Surface Characteristics of Direct Fluorinated Single-walled Carbon Nanotubes
}

\author{
Min-Kang Seo and Soo-Jin Park-

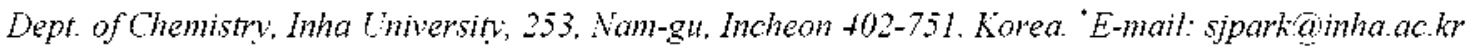 \\ Received June 17, 2009, Accepted August 3, 2009
}

\begin{abstract}
The single-walled carbon nanotubes (SWCNTs) produced by chemical vapor deposition (CVD) were directly fluorinated with fluorine $\left(\mathrm{F}_{2}\right)$ gas in a temperature range $20-400^{\circ} \mathrm{C}$. The surface properties and morphology of the SWCNTs were investigated in tenns of fluorination temperature. As a result, Raman spectra showed a pair of bands at 1340 and $1590 \mathrm{~cm}^{-1}$ peculiar to disordered $\mathrm{sp}^{2}$-carbons. These results indicated that C-F bonds were formed on the rear surfaces of the nanotubes by fluorination, while the external surfaces as well as the layers between the intenal and extenal surfaces retained their $\mathrm{sp}^{2}$-hybridization. XPS analy sis exhibited that fluorine atoms were bonded to carbon atoms on intemal surfaces (rear surfaces) of the nanotubes and the amount of fluorine attached on the nanotubes was increased with increasing the fluorination temperature. Consequently, the direct fluorination of carbon nanotubes led to functionalization and modification of pristine nanotubes with respect to surface and morphological properties.
\end{abstract}

Key Wonds: Raman spectroscopy, X-ray photoelectron spectroscopy. Thermogravimetric analysis. Electrical properties. Transmission electron microscopy

\section{Introduction}

Since the discovery of carbon nanotubes (CNTs). there has been flury of research activities aimed at understanding their physical properties. elucidating their growth mechanisms and developing novel uses for them. However. physics and chemistry involving CNTs are still in their infancy. This is due. in large part, to previous difficulties in obtaining reasonable quantities of highly purified CNTs. ${ }^{1}$

Single-wall carbon nanotubes (SWCNTs) have generated a great deal of interest due to their exceptional physical properties and possessing a chemical stability akin to that of the basal plane of graphite by virtue of their aromatic nature. This is why SWCNTs have been proposed as promising materials for a variety of applications. including in polymer reinforcement. ${ }^{2}$ field effect devices. ${ }^{3}$ electrochemical energy' storage. ${ }^{4}$ catalyst supports for fuel cells. ${ }^{5}$ sensors and actuators, ${ }^{6}$ and molecular electronics. Especially. SWCNTs represent attractive possibilities for developing newly strong composite materials. since both experimental studies and theoretical modeling have demonstrated that SWCNTs have extremely high Young's modulus. stiffness, and flexibility. ${ }^{8-10}$

However. if these materials are to be utilized as effective reinforcements in advanced composites. good chemical, and physical bonds to the matrix must exist. to effectively transfer mechanical loads from the matrix to the nanotubes and thus take advantage of their mechanical features. Accordingly, the treatment for introducing of new functional groups to the open-end-cap carbon nanotubes has been necessitated.

Margrave and co-workers first reported the fluorination of purified end-closed SWCNTs. " This subject is of great interest for a wide variety of sidewall chemical functionalizations. The fluorination was carried out on the purified SWCNTs prepared by the dual-pulsed laser vaporization of $\mathrm{Co} / \mathrm{Ni}$ doped graphite rods in the temperature range $150 \sim 600^{\circ} \mathrm{C}$ for $5 \mathrm{~h}$. using elemental fluorine diluted with helium. The stoichiometries. by gravimetry. of the products fluorinated at 150,250 . 325, and $400{ }^{\circ} \mathrm{C}$ were $\mathrm{CF}_{0.114}, \mathrm{CF}_{(1521}, \mathrm{CF}_{10.495}$, and $\mathrm{CF}_{(1565 .}$ respectively. $\mathrm{C}_{4} \mathrm{~F}$ is the limiting stoichiometry for which the outside wall fluorinated SWCNTs can still maintain a tube-like structure. In further work. Mickelson et al. have shown that fluorinated SWCNTs (F-SWCNTs) dissolve well in alcohol solvents to give long-living metastable solutions. " Consequently. interesting routes to prepare a wide variety of functionalized nanotubes have been developing through the solution chemistry of F-SWCNTs. ${ }^{13.14}$ The fluorination was reported for conmercially available multiwall carbon nanotubes (MWCNTs).

Direct fluorination is one of the most effective chemical methods to modify and control physicochenical properties of carbon materials. The method is rather straightforward. but the interpretation of the results is not necessarily easy. The complication lies in the diversity of carbon materials and wide-range C-F bond nature. This conversely gives an opportunity to control properties of carbon materials in a wide range. either gradually or drastically.

Fluorine directly reacts with graphite at temperatures greater than $300^{\circ} \mathrm{C}$. yielding physically bonded $(\mathrm{CF})_{n 1}$ and $\left(\mathrm{C}_{2} \mathrm{~F}\right)_{\mathrm{n}}$ with $\mathrm{sp}^{3}$ hybridization. At temperature less than $300^{\circ} \mathrm{C}$ the reaction rate of fluorine with graphite is drastically reduced. On the other hand. fluorine has been found to intercalate graphite at low temperature (around $100^{\circ} \mathrm{C}$ in the presence of traces of fluorides such as hydrogen fluoride $(\mathrm{HF})$ to form intercalation compounds $\mathrm{C}_{\mathrm{K}} \mathrm{FH}_{\delta}$. in which carbon retains its $\mathrm{sp}^{2}$ hybridization. In this work, thus. one of the technologies developed in the modification of SWCNTs. we execute a direct fluorination on SWCNTs to investigate the effect of direct fluorination on changes of properties of fluorinated SWCNTs at different fluorination temperatures. 


\section{Experimental}

Materials. Single-walled carbon nanotubes (SWCNTs) studied in this work were manufactured by CVD process (CVD SWCNTs. supplied from iljin nanotech Co. of Korea. degree of purity is $>90 \sim 94 \%$ length: $5 \mu \mathrm{m}$. diameter: 0.8 nm). The $F_{2}$ and $N_{2}$ gases used were $99.99+\%$ pure.

Sample preparation. SWCNTs were subjected to fluorination in several different fluorination temperatures. The fluorination reaction was performed in a batch reactor made of nickel with an outer electric funace. Prior to fluorination the chamber was pumped out to a basal pressure of $10 \mathrm{mtorr}$ and purged by' nitrogen gas to remove the residual oxygen gas and moisture. After evacuation. the fluorine ( $\left.\mathrm{F}_{2}\right)$ gas was introduced to the reactor at room temperature. and then the reactor was heated to the treatment temperature. The fluorine pressure was 1 $\mathrm{MPa}$ and the nominal reaction time was $\mathrm{I} \mathrm{h}$ at the treatment temperature. After the reaction. the chamber was pumped out again to $10 \mathrm{mtorr}$ and nitrogen gas was refilled prior to the extraction of the samples.

Characterizations. Raman scattering measurements were performed by a spectrometer in a micro mode (T64000. Atago-Jobin Yvon. $\mathrm{Ar}^{+}$laser with the excitation wavelength of $514.5 \mathrm{~nm}$ ). the diameter of the analyzed region being $\sim 1 \mu \mathrm{m}$. The X-ray photoelectron spectroscopy (XPS) measurement of nanotube surfaces was performed using a VG Scientific ESCA LAB MK-II spectrometer equipped with a Mg-Ka X-ray source. The base pressure in the sample chamber was controlled in the range of $10^{-8}$ to $10^{-9}$ torr. The resulting surface element concentrations of fluorinated nanotube samples were listed in Table 1. Product stoichiometries of the samples as a function of reaction temperature were obtained by both gravimetrically (TA Instrument TGA-DTA 2960 microbalance) and electron microprobe analy sis (Cameca $\mathrm{SX}-50$ ).

The two-point method was used for the measurement of resistance of the samples. The samples were prepared by compression-molded at 7.5 MPa without any binder to measure the resistance of fluorinated SWCNTs. The prepared samples were pellet type with about $10 \mathrm{~mm}$ in diameter and $1 \mathrm{~mm}$ in thickness. Copper paste and conductive binder were used to ensure good contact of the sample surface with the electrodes of the conduction tester. which reduce the problems caused by contact resistance. The constant current passing through the nanotubes was $20 \mu \mathrm{A}$. The specific resistance was calculated by using the equation (1) taking into account the diameter and the length of the specimens. Measurement of five times at the same sample was carried out to decrease the experimental error of the test.

$$
\rho=R \pi \frac{(d / 2)^{2}}{l}-\frac{R \pi d^{2}}{4 l}=\frac{1}{k}
$$

where $k$ is the specific conductivity.

Changes in the surface morphology' of fluorinated SWCNTs were examined using scanning electron micrographs (SEM. JEOL JSM-840A using $5 \mathrm{keV}$ beam energy). The materials obtained before and after the fluorination were characterized by high-resolution transmission electron microscopy (HRTEM.
Talble 1. Reaction product stoichiometries detemined by both gravimetric and electron microprobe analyses

\begin{tabular}{ccccc}
\hline \multirow{2}{*}{ Methods } & \multicolumn{5}{c}{ Reaction temperature $\left({ }^{\circ} \mathrm{C}\right)$} \\
\cline { 2 - 5 } & $\mathrm{RT}$ & 100 & 300 & 400 \\
\hline Gravimetric & $\mathrm{CF}_{0102}$ & $\mathrm{CF}_{(1114}$ & $\mathrm{CF}_{(1+145}$ & $\mathrm{CF}_{(1555}$ \\
Microprobe & $\mathrm{CF}_{0.093}$ & $\mathrm{CF}_{0.097}$ & $\mathrm{CF}_{0.55+}$ & $\mathrm{CF}_{0.5+7}$ \\
\hline
\end{tabular}

JEOL model 2010 TEM using $100 \mathrm{keV}$ beam energy). Samples were prepared adding methanol and dispersing the suspended tubes in an ultrasonic bath. After ultrasonification, a drop of the suspension was placed on a microgrid and dried in air before TEM observation.

\section{Results and Discussion}

Raman spectroscopy. The characteristic Raman spectnum of untreated SWCNTs is shown in Figure 1 (a). with the strongest Raman bands at $\sim 186,1565$ and $1587 \mathrm{~cm}^{-1} .{ }^{16.77}$ The smaller peak at $186 \mathrm{~cm}^{-1}$ corresponds to the $A_{1 g}$ radial breathing mode of the SWCNTs. indicating the enrollment of graphene sheets in the SWCNTs. The frequency of this peak is dependent on the nanotube diameter. ${ }^{18}$ The $186 \mathrm{~cm}^{-3}$ frequency corresponds to a radius of curvature $\sim 1.2 \mathrm{~nm}$. Two peaks at $\sim 1565$ and $\sim 1587 \mathrm{~cm}^{-1}$ correspond to $E_{2 g}$ and $A_{1 g}$ modes characteristic of SWCNTs. respectively.

Raman spectra of fluorinated SWCNTs at reaction temperatures of 100.300 , and $400^{\circ} \mathrm{C}$ are also shown in Figure 1. As mentioned above. the smaller peak near $186 \mathrm{~cm}^{-1}$ of undoped and fluorinated SWCNTs at $100^{\circ} \mathrm{C}$ is due to a characteristicbreathing mode of the SWCNTs. This breathing mode is suppressed by F-doping up to $100^{\circ} \mathrm{C}$. Also. fluorination causes a sluft as well as sharpening or disappearing of the D- and

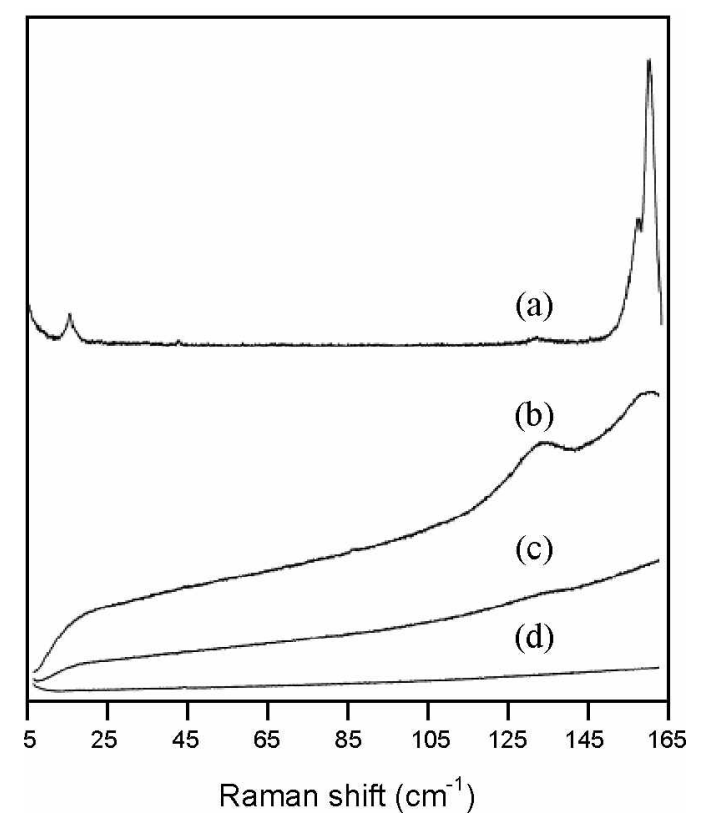

Figure 1. Raman spectra of SWCNTs as a function of fluorination temperature: (a) No treatment, (b) SWCNTs-100, (c) SWCNTs-300, and (d) SWCNTs-400. 
G-band of fluorinated SWCNTs. Trace (b). corresponding to the reaction at $100^{\circ} \mathrm{C}$. shows only two broad peaks centered around 1340 (D-band) and $1580 \mathrm{~cm}^{-1}$ (G-band) and a broadband fluorescence. The Raman peaks correspond to $\mathrm{sp}^{3}$ and $\mathrm{sp}^{2}$ carbon stretching modes. respectively. The peak at $\sim 1565$ $\mathrm{cm}^{-1}$ is disappeared in the Raman spectra of the samples fluorinated over $300^{\circ} \mathrm{C}$ for $\mathrm{l} \mathrm{h}$, and the peak at $\sim 186 \mathrm{~cm}^{-1}$ is also decreased in its intensity. A very weak feature at $\sim 1350 \mathrm{~cm}^{-1}$ in the fluorinated samples corresponds to the D-band. typical of glassy carbons or disordered graphite. The D-band at 1347 $\mathrm{cm}^{-1}$. also decreases its intensity in the samples fluorinated over $300^{\circ} \mathrm{C}$ for $1 \mathrm{~h}$. After fluorination at $300^{\circ} \mathrm{C}$. all the Raman characteristic peaks of SWCNTs become extinct. The evolution of the D-band suggests that the disordering of the SWCNT structure occurs over $300^{\circ} \mathrm{C}$. and at higher temperature. a reordering of carbon atoms takes place. ${ }^{17}$ Also. the $I_{G} / I_{\mathrm{D}}$ peak intensity ratios are deceased with increasing fluorination temperature, indicating change in their structural properties in the bulk after fluorination.

Consequently, Raman spectroscopy confirms the formation of new inter- and intra-molecular bonds to the nanotube superstructure.$^{19}$ Contributions of adsorbed molecular fluorine to the overall fluorine uptake are precluded at these temperatures. Therefore, we have demonstrated that large amounts of fluorine are attached to the side-wall of the SWCNTs

Surface characteristics. Lee et $a^{120}$ reported that Infrared spectroscopy ( $\mathrm{KBr}$ pellet method) can confirm the presence of bound fluorine (peaks in the $1220.1250 \mathrm{~cm}^{-1}$ region) in the samples fluorinated at temperatures of $150^{\circ} \mathrm{C}$ and higher. No $\mathrm{C}-\mathrm{F}$ stretching frequency is seen for the sample fluorinated at RT. and its two-point resistance ( $5 \mathrm{~mm}$ apart) is $\sim 15 \Omega$ which therefore can preclude large amounts of fluorine being functionally bound to the SWCNT sidewall. Therefore, we calculated product stoichiometries of the fluorination reactions and listed in Table 1. Discrepancy between the gravimetric and microprobe analyses can be attributed to the product decomposition. especially at the elevated temperatures.

Figure 2 shows the XPS $\mathrm{C}_{1 s}$ and $\mathrm{F}_{1 \mathrm{~s}}$ spectra of fluorinated SWCNTs at different fluorination temperatures. With increasing the temperature. both $C_{1:}$ and $F_{1 s}$ peaks assigned to fluorine functional groups shift to higher binding energy and their intensities become stronger. ${ }^{31}$ And these spectra show symmetric shapes. compared to those of fluorinated carbon fibers. ${ }^{\text {t- }}$ However, the binding energy remains almost constant within $687.5 \mathrm{eV}$ at a fluorination temperature up to $100^{\circ} \mathrm{C}$ and then the binding energy shifts to near $689 \mathrm{eV}$ over the temperature $300{ }^{\circ} \mathrm{C}$. The latter peak is similar to that of tetrafluoroethylene. which has a strong intramolecular bonding. ${ }^{33}$ The significant shift in the binding energy for the sample fluorinated at elevated temperatures indicates that the bonding nature of the samples fluorinated at low temperatures $<100^{\circ} \mathrm{C}$ is very different from the simple chemical bonding character.

Consequently the amount of doped fluorine increases with increasing the fluorination temperature. and the fluorine atoms can be physically (van der Waals bonding) attached to the sidewall of the SWCNTs. If some part of SWCNTs is destroyed by fluorination at elevated temperature. the inside of nanotubes can be able to be fluorinated. However. we cannot experimentally confirm whether or not fluorine is doped on inside of them.

The surface compositions $(\mathrm{F} / \mathrm{C})$ determined by peak areas (at\%) of high-resolution curve fitted $C_{1 s}$ and $F_{1 s}$ XPS spectra are listed in Table 2 . The value increases with increasing the temperature and reaches close to 0.41 at $300{ }^{\circ} \mathrm{C}$. in good agreements with our previous reports, although the experimental fluorination condition is somewhat different from each other. ${ }^{21.24}$ At $400^{\circ} \mathrm{C}$. however, the value only reaches to 0.43 since $\mathrm{CF}_{x}$ conposition with $x>0.5$ is prohibited in the sidewall fluorination due to electrostatic repulsion between fluorine atoms
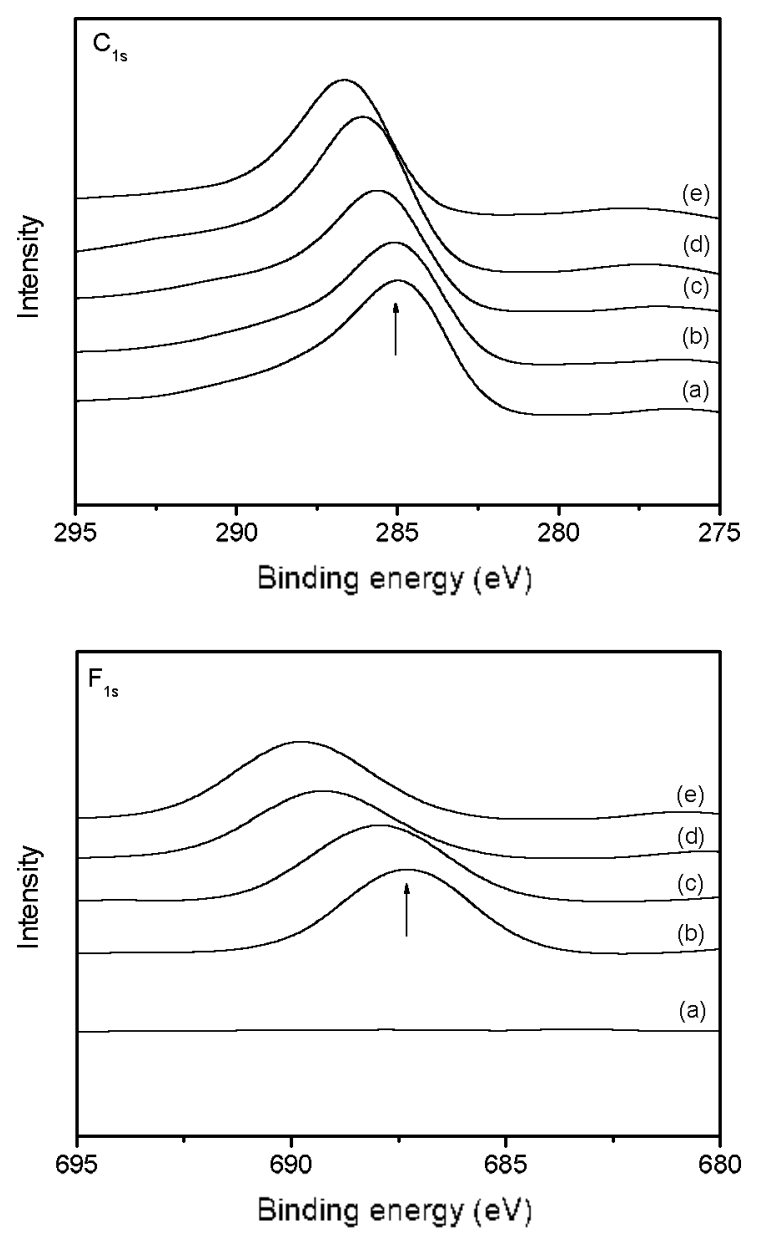

Figure 2. $C_{1 s}$ and $F_{1 s}$ narrow XPS spectra of SWCNTS as a function of fluorination temperature: (a) No treatment, (b) SWCNTs-RT, (c) SWCNTs-100, (d) SWCNTs-300, and (e) SWCNTs-400.

Table 2. Surface chemical concentrations of SWCNTs as a function of fluorination temperature

\begin{tabular}{lccc}
\hline \multirow{2}{*}{ Samples } & \multicolumn{3}{c}{ Elemental contents (at\%) } \\
\cline { 2 - 4 } & C & F & F/C ratio \\
\hline No treatment & 92.38 & - & - \\
SWCNTs-RT & 82.81 & 5.68 & 0.06 \\
SWCNTs-100 & 80.40 & 12.05 & 0.15 \\
SWCNTs-300 & 68.37 & 27.42 & 0.41 \\
SWCNTs-400 & 66.53 & 28.79 & 0.43 \\
\hline
\end{tabular}


(a)

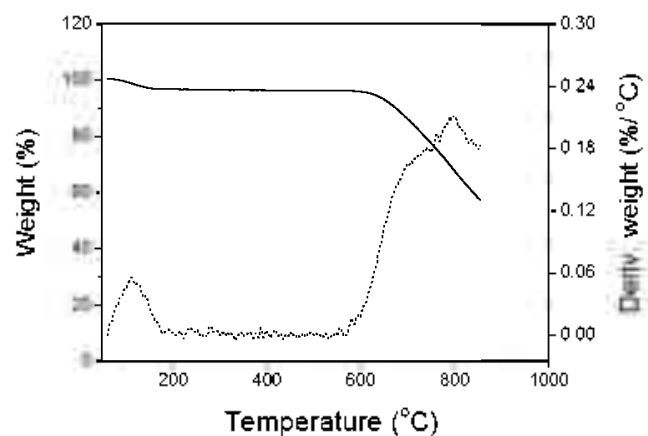

(b)

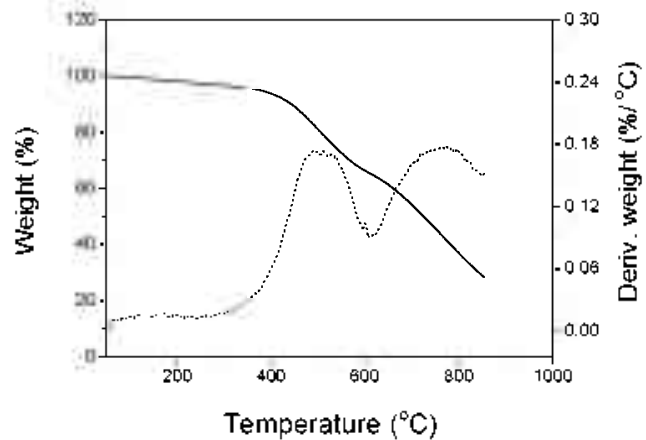

(c)

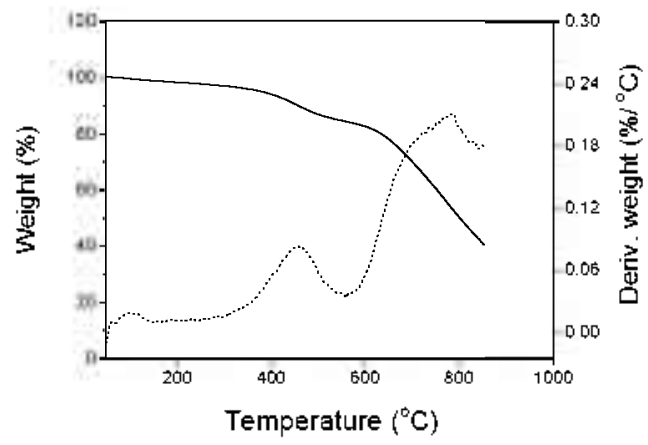

(d)

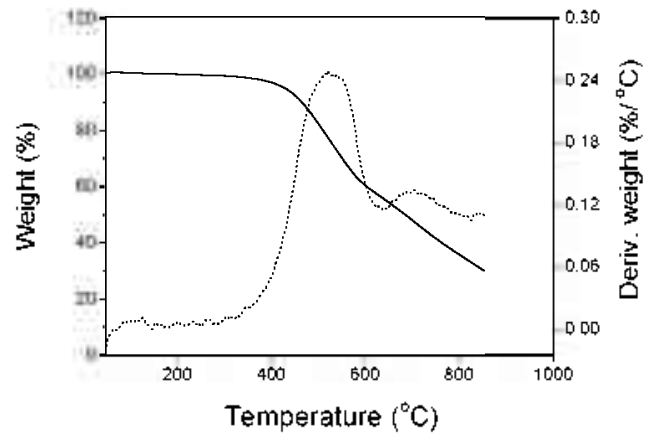

(e)

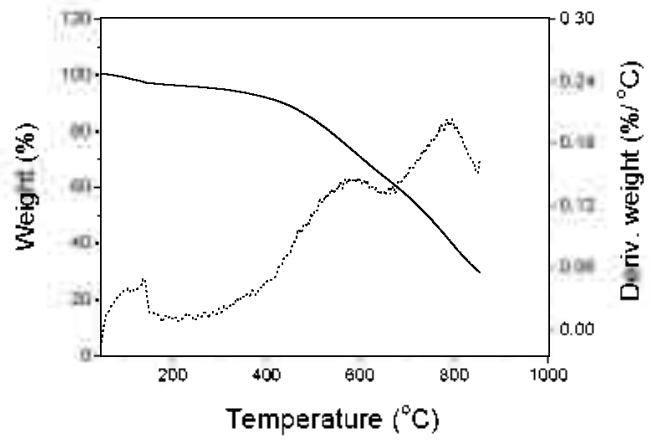

Figure 3. TGA themmograms of SWCNTs as a function of thorination temperature: (a) No treatment, (b) SWCNTs-RT, (c) SWCNTs-100, (d) SWCNTs-300, and (e) SWCNTs-400.
TGA analysis. The TGA results of SWCNTs after fluorination are shown in Figure 3. where solid lines show the weight loss as a function of temperature from 30 to $850^{\circ} \mathrm{C}$ and dot lines are corresponding derivative curves which directly reflect variation in the weight with temperature. The untreated SWCNTs shows one broad curve at maximum peak temperature $795^{\circ} \mathrm{C}$. which corresponds to the SWCNTs burning. However, the TGA derivative curve for fluorinated SWCNTs at $300^{\circ} \mathrm{C}$ has two peaks at about 520 and $710^{\circ} \mathrm{C}$. These indicate that the fluorination leads to a decrease of thermal stability of SWCNTs, although product stoichiometry of fluorination reaction for fluorinated SWCNTs is increased.

Electrical properties. Figure 4 shows the specific resistivity of fluorinated SWCNTs measured by two-point probe method at room temperature. It can be seen that the resistivity is increased with increasing the fluorination temperature. i.e., the fluorine doping content corresponding to the similar trend of the reaction product stoichiometric data, as listed in Table 1. Not unexpectedly, the electronic properties of fluorinated tubes differ drantatically from those of their unfluorinated counterparts. While untreated SWCNTs are good conductors, the nanotubes fluorinated at the temperatures of $300^{\circ} \mathrm{C}$ and above are somewhat insulators. In other words. the electronic properties are altered by fluorination to decrease the conductivity of the individual SWCNTs. ${ }^{20}$

Morphologies. Figure 5 shows the SEM results of purified starting materials and the same materials after fluorination at

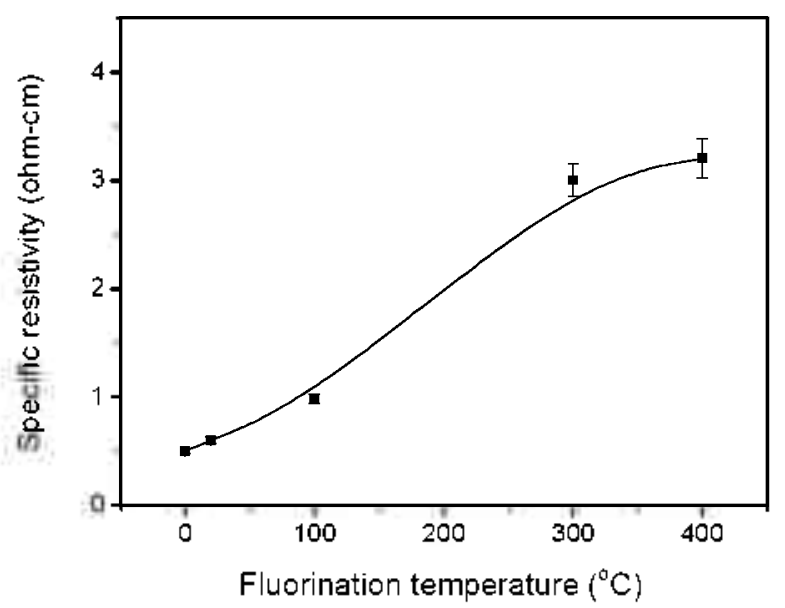

Figure 4. Specific resistivity of SWCNTS as a function of fluorination temperature, measured by two-point probe method at room temperature.

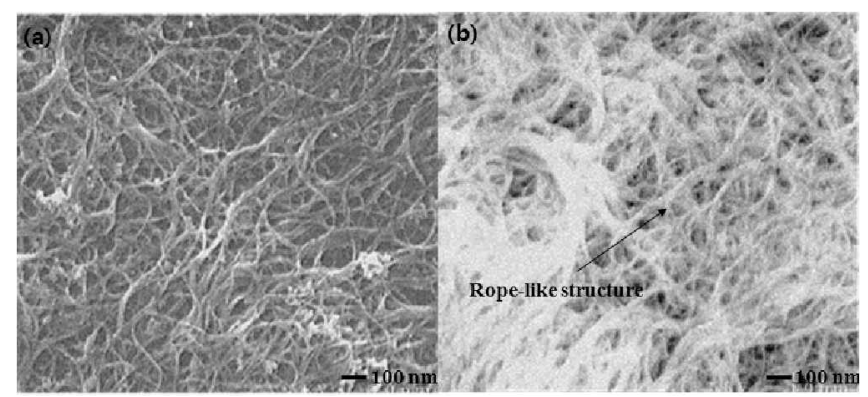

Figure 5. SEM images of pristine and SWCNTs fluorinated at 300 ${ }^{\circ} \mathrm{C}$ : (a) No treatment and (b) SWCNTs-300. 


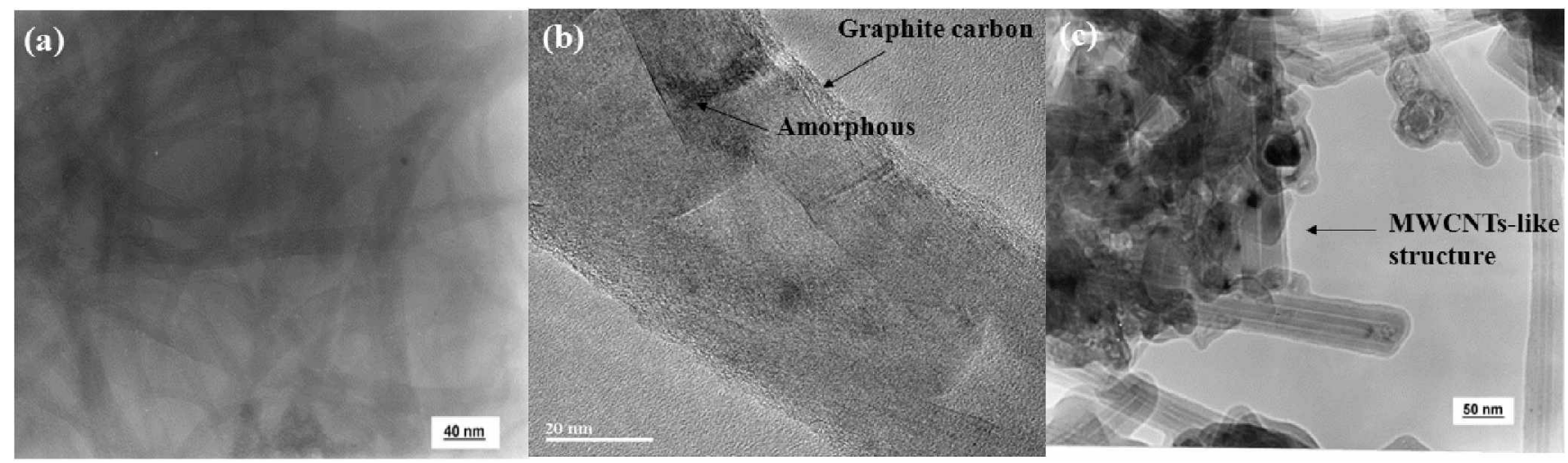

Figure 6. HRTEM images of pristine and SWCNTs fluorinated at $300{ }^{\circ} \mathrm{C}$ and $400^{\circ} \mathrm{C}$ : (a) No treatment, (b) SWCNTs-300, and (c) SWCNTs-400.

$300^{\circ} \mathrm{C}$ for $1 \mathrm{~h}$. The SEM images show excessive charging due to its insulating nature. as can be seen from Figure 1 (b). however the rope-like stnicture of nanotubes is still evident and remains largely intact after fluorination at $300^{\circ} \mathrm{C}$.

Figure 6 shows HRTEM images of the untreated and/or fluoninated SWCNTs at $300^{\circ} \mathrm{C}$ and $400^{\circ} \mathrm{C}$. HRTEM observation of unfluorinated SWCNTs (Figure 6(a)) shows a homogeneous sample: tube diameters are $-0.8 \mathrm{~nm}$. as indicated by the Raman shift of the radial breathing mode. Nanotube bundles have diameters ranging from 5 to $15 \mathrm{~nm}$ and length exceeding tens of micrometers. The ratio between diameter and length is higher than 1000 . The presence of nanotubes is also observed in the as-received purified sample. The morphology of the material changes completely after the fluorination at $300{ }^{\circ} \mathrm{C}$ for $\mathrm{I} \mathrm{h}$ (Figure 6 (b)). The sample converts to a mixture of amorphous and graphitic carbon, with nanotube-like structures and crystalline clusters embedded in an amorphous carboncarbon matrix. We could not obtain clearer TEM image of SWCNT lattice fringes because of the coverage of the amorphous carbon on the bundles. Also the HRTEM image of SWCNTs fluorinated at $400^{\circ} \mathrm{C}$ (Figure 6 (c)) shows that these bundles are transformed into multiwall-like phase stnictures. Mickelson $e t a{ }^{11}$ have reported that the SWCNTs fluorinated at $500{ }^{\circ} \mathrm{C}$ are essentially all destroyed, and some MWCNTs-like structures are generated.

As can be seen from these images. it is also found that nanotube phase is changed during the TEM observation of fluorinated SWCNTs. The phase transformation such as MWCNTs-like. onion and graphitic structure takes place owing to the electron beam-induced. which is never observed from the undoped nanotubes. Besides the graphitic-layered phases. we also observe an amorphous and turbostratic phases (Figure 6).

The fluorination of MWCNTs has been reported previously which were done at two temperatures: 25 and $500{ }^{\circ} \mathrm{C}$. The room temperature reaction was done with $F_{4}, H F$. and $F_{5}$ mixtures and yielded intercalated type compounds. The reaction carried out at $500^{\circ} \mathrm{C}$ was done with $\mathrm{F}_{2}$. and was determined to have destroyed the tube stnicture to yield graphite fluoride compounds of stoichiometry, C-F. In view of this, it is not too surprising that we observe the destruction of the SWCNTs at 400 "C . but somewhat surprising that the
MWCNTs-like structures are formed in the present experimental condition.

\section{Conclusions}

XPS results showed that the amount of doped fluorine was increased with increasing the fluorination temperature, and the fluorine atoms were effectively attached to the surface or sidewall of the SWCNTs.

From Raman spectra analysis. the strong fluorination on the SWCNTs led to a breaking of carbon-carbon bonds and disintegration of tube structures. SEM images showed that the morphology of SWCNTs after fluorination at $300^{\circ} \mathrm{C}$ showed an excessive charging due to its insulating nature, but the rope-like structure of tubes was still existed in the present conditions. TEM studies exlibited that the structure of SWCNTS converted to a mixture of amorphous and graphitic carbon after fluorination at $300^{\circ} \mathrm{C}$. And the sample at $400^{\circ} \mathrm{C}$ could probably be presented of the formation of MWCNTs-like structures. Consequently a direct fluorination was proven to be one of effective methods to modify surface, electrochemical. and morphological properties of the carbon nanotubes.

Acknowledgments. This work was supported by Inha University Research Grant

\section{Refeiences}

1. Iijima, S.; Ichihashi, T. Kature 1993,363,603.

2. Velasco-Santos, C.; Martínez-Hemandez, A. L.: Lozada-Cassou, M.; Alvarez-Castillo, A.; Castaño, V. M. Nonotechology 2002, 13,495

3. Bonard, J. M.; Kind, H.; Stôckli, T.; Nilsson, L. O. Solid-State Electron 2001, 45, 893.

4. Elzbieta, F.: François, B. Carbon 2002, 40,1775

5. Wenzhen, L.; Changhai, L.; Jieshan, Q.; Weijiang, Z.; Hongmei, H.: Zhaobin, W: Gongquan, S.: Qin, X. Carbon 2002, 40,791

6. Peifang, L.; Turhu, H. Sens. Actuators B 2002, 8t, 194.

7. Tucknott, R, Yaliraki, S. N. Chem. Phys. 2002, $281,455$.

8. Argon, A. S. Fractwe: Strength and tonghmess itechanisms. In Comprehensive Conposite haterials; Elsevier: New York, 2000; Vol. 1, p 24.

9. Krishnar1, A.; Dujardin, E:- Ebbesen, T. W: Yanilos, P. N.; Treacy, M. M. Phys. Rev B 1998, 58, 14013. 
10. Yu, M. F.: Files, B. F.: Arepalli, S.; Ruotf, R. S. Phys. Rev Lett. $2000,84,5532$.

11. Mickelson, E. T.; Huffman, C. B.: Rinzler, A. G.: Smalley, R. E. Hauge, R. H.: Margrave, J. L. Chent. Phes. Lent. 1998, 296, 188.

12. Mickelson. E. T. Chiang, I. W.: Zimmeman, J. L.: Boul, P. J.; Lozano, J.: Lin, J.: Smally, R. E.; Hauge, R. H.; Margrave, J. L. J. Phy Chem. B 1999,103,4318.

13. Kelly, K. F: Chiang, I. W: Mickelson, E. T: Hauge, R. H.; Margrave, I. L.; Wang, X.; Scuseria, G. E.; Radlofi, C.; Halas, N. T. Chem Phys Lett $1999,313,445$.

14. Boul, P. J.: Liu, I.; Mickelson, E. T.: Huffnan, C. B.: Erickson, L. M.; Chiang, I. W: Smith, K. A.; Colbert, D. T.; Hauge, R. H.: Margrave, J. L.; Smally, R. E. Chem. Phys. Lett. 1999, 310, 367.

15. Chamssedine, F.; Claves, D. Chem. Phys. Lett 2008, $454,252$.

16. Saito, R.: Dresselhans, G.: Dresselhans, M. S. In Phssical Properties of Carbon Kanotubes: Inperial College Press: London, 1998.
17. Lamy de la Chapell, M.; Lefrant, S.: Jounet, C.: Maser, W: Benier, P. Carbon 1998, 36, 705.

18. Pelletier. M. I. In Anatutical ipplications of Raman Spectroscopv, Blackwell; Oxford, 1999.

19. Swamy, S. S.; Calderon-Moreno, T. M.; Yoshimura, M. J. Moter: Res. 2002, 17, 734

20. Lee. Y. S.: Cho. T. H.: Lee. B. K.: Rho, I. S.: An. K. H.: Lee. Y. H. J. Fllo. Chem. 2002, 120,99

21. Park, S. J.; Seo, M. K.; Lee, Y. S. Carbon 2003, $11,723$.

22. Mickelson, E. T.: Huffiman, C. B.; Rinzler, A. G.: Smalley, R. E.; Hange, R. H.; Margrave, J. L. Chem. Phus. Lett. 1998, 296, 188.

23. Wu, S, Kang, E. T.; Neol, K. G. Appl. Suf, Sci. 2001, 17t, 296.

24. Park, S. J.; Seo, M. K.; Rhee, K. Y. Mlater: Sci. Eng. A 2003, 356 , 219.

25. Hamwi, A:; Alvergnat, H.: Bonnamy, S.: Béguin, F. Canbon $1997,35,723$. 